\begin{tabular}{|c|c|c|}
\hline 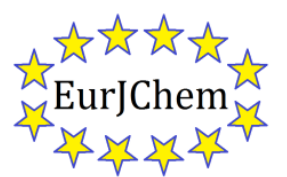 & $\begin{array}{c}\text { European Journal of Chemistry } \\
\text { Journal homepage: } \underline{w w w . e u r j c h e m . c o m ~}\end{array}$ & 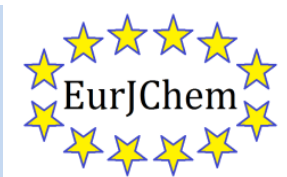 \\
\hline
\end{tabular}

\title{
Thiazole derivatives as corrosion inhibitors for C-steel in sulphuric acid solution
}

\author{
Abd El-Aziz Foudaa, Ahmed Al-Sarawyb and Emad El-Katoric,* \\ a Department of Chemistry, Faculty of Science, Mansoura University, Mansoura, EG-35516, Egypt \\ $\mathrm{b}$ Department of Mathematical and Physical Science, Faculty of Engineering, Mansoura University, Mansoura, EG-35516, Egypt \\ c Department of Chemistry, Faculty of Science, King Khalid University, Abha, SA-61413, Saudi Arabia \\ *Corresponding author at: Department of Chemistry, Faculty of Science, King Khalid University, Abha, SA-61413, Saudi Arabia. Tel.: +966.5.61365264; \\ fax: +966.7.2282766. E-mail address: emad 992002@yahoo.com (E. El-Katori).
}

\section{ARTICLE INFORMATION}

Received: 10 May 2010

Received in revised form: 24 August 2010

Accepted: 30 September 2010

Online: 31 December 2010

\section{KEYWORDS}

Corrosion inhibitors

C-steel

Weight loss

Synergistic effect

Polarization

Thiazole derivatives

\begin{abstract}
5-phenylazo-2-thioxo-thiazolidin-4-one and four of its derivatives have been investigated as corrosion inhibitors for $\mathrm{C}$-steel in $1 \mathrm{M}$ sulphuric acid solution using weight-loss and galvanostatic polarization techniques. The efficiency of the inhibitors increases with increase in inhibitor concentration but decreases with a rise in temperature. The conjoint effect of the thiazole derivatives and $\mathrm{KBr}$, KSCN and $\mathrm{KI}$ has also been studied. The apparent activation energy $\left(E_{\mathrm{a}}{ }^{*}\right)$ and other thermodynamic parameters $\left(\Delta S^{*}, \Delta H^{*}\right.$ and $\Delta G^{*}$ ads $)$ for the corrosion process have also been calculated. The galvanostatic polarization data indicated that, the inhibitors were of mixed-type, but the cathode is more polarized than the anode. The slopes of the cathodic and anodic Tafel lines ( $\beta_{c}$ and $\beta_{a}$ ) are approximately constant and independent of the inhibitor concentration. The adsorption of these compounds on C-steel surface has been found to obey the Temkin's adsorption isotherm. The mechanism of inhibition was discussed in the light of the chemical structure of the undertaken inhibitors.
\end{abstract}

\section{Introduction}

Corrosion and corrosion inhibition of iron and iron alloys, in general, and steel in particular, have been received a great attention in different media [1-5] with and without various types of inhibitors. The corrosion inhibition of C-steel becomes of such interest to do because of its widely use as a constructional material in many industries and this is due to its excellent mechanical properties and low cost.

A number of studies have recently appeared in the literature [6-10] on the topic of the corrosion inhibition of Csteel in acidic media. But little work appears to have been done on the corrosion inhibition of steel alloys in sulphuric acid using thiazole derivatives.

The present work was designed to study: i) corrosion inhibition of C-steel in hydrochloric acid solutions by some thiazole derivatives using weight-loss and galvanostatic polarization techniques, ii) the effect of substituted groups on the inhibition efficiency and also iii) the effect of temperature on the corrosion rate in order to calculate some thermodynamic parameters related to the corrosion process.

\section{Experimental}

\subsection{Materials}

The experiments were performed with C-steel having the chemical compositions given in the following Table 1 . The inhibitors used in this study were selected from thiazole derivatives and given in Scheme 1.<smiles>[X]c1ccc(/N=N/C2SC(=S)NC2=O)cc1</smiles>

$X:-\mathrm{OCH}_{3},\left(A_{1}\right) ;-\mathrm{CH}_{3},\left(A_{2}\right) ;-\mathrm{H},\left(A_{3}\right) ;-\mathrm{Cl},\left(A_{4}\right) ;-\mathrm{NO}_{2},\left(A_{5}\right)$

Scheme 1

Table 1. Chemical composition of C-steel.

\begin{tabular}{ll}
\hline Element & Weight (\%) \\
\hline $\mathrm{C}$ & 0.200 \\
$\mathrm{Mn}$ & 0.350 \\
$\mathrm{P}$ & 0.024 \\
$\mathrm{Si}$ & 0.003 \\
$\mathrm{Fe}$ & The rest \\
\hline
\end{tabular}

\subsubsection{Preparation of inhibitors used}

Thiazole derivatives $\left[A_{1-5}\right]$ were prepared by adding 0.01 mole of sodium nitrite acidified with $1: 1 \mathrm{HCl}$ dropwise with gradual stirring to the hydrochloric acid solution of 0.01 mole of both [ $p$-methoxy aniline, $p$-methyl aniline , aniline, $p$-chloro aniline $\& p$-nitro aniline] $[11,12]$ and kept for about 20 minutes in ice bath .The formed diazonium chloride solution was added gradually with vigorous stirring to a 0.01 mole cold solution of 2-thioxo-thiazolidin-4-one in $20 \mathrm{~mL}$ pyridine containing $5 \mathrm{~g}$ sodium acetate, respectively. After dilution the thiazole compounds formed were recrystallized from ethyl alcohol and then dried in vacuum desiccators over anhydrous calcium chloride. 
The important IR spectra bands of studied inhibitors $\left(A_{1-5}\right)$ are presented and discussed. $v(\mathrm{~N}=\mathrm{N}$ azo function $)$ symmetric stretching vibration appears in $1530-1540 \mathrm{~cm}^{-1}$ region. A broad band centered in the $1100-1150 \mathrm{~cm}^{-1}$ region assigned thiocarbonyl on $v(\mathrm{C}=0)$ symmetric stretching vibration saturated ketone appears in $1420-1450 \mathrm{~cm}^{-1}$ region [11,12].

$100 \mathrm{~mL}$ stock solutions $\left[10^{-3} \mathrm{M}\right]$ of compounds $\left[\mathrm{A}_{1-5}\right]$ were prepared by dissolving an accurately weighed quantity of each material in an appropriate volume of absolute ethanol, then the required concentrations $\left[1 \times 10^{-6}-11 \times 10^{-6} \mathrm{M}\right]$ were prepared by dilution with bidistilled water.

Sulphuric acid solution was prepared by diluting the appropriate volume of the concentrated chemically pure acid (BDH grade), with bidistilled water and its concentration was checked by standard solution of $\mathrm{Na}_{2} \mathrm{CO}_{3}$.

Two different techniques have been employed for studying the corrosion inhibition of C-steel by thiazole derivatives, these are: i) Chemical technique (weight-loss method) and ii) Electrochemical technique (galvanostatic polarization method).

\subsection{Chemical technique (Weight-loss method)}

The reaction basin used in this method was graduated glass vessel $6 \mathrm{~cm}$ inner diameter and having a total volume of 250 $\mathrm{mL} .100 \mathrm{~mL}$ of the test solution were employed in each experiment. Three test pieces were cut into $2.0 \times 2.0 \times 0.2 \mathrm{~cm}$. They were mechanically polished with emery paper (a coarse paper was used initially and then progressively finer grades were employed), degreased in acetone [13], rinsed with bidistilled water and finally dried between two filter papers and weighed. The test pieces were suspended by suitable glass hooks at the edge of the basin, and under the surface of the test solution by about $1 \mathrm{~cm}$. After specified periods of time, the three test pieces were taken out of the test solution, rinsed with bidistilled water, dried as before and weighed again. The average weight loss at a certain time for each set of three samples was taken. The weight loss was recorded to the nearest $0.0001 \mathrm{~g}$.

\subsection{Electrochemical technique (galvanostatic polarization method)}

Three different types of electrodes were used during polarization measurements: The working electrode was C-steel electrode, which cut from C-steel sheets, thickness $0.2 \mathrm{~cm}$. The electrode was of dimensions $1.0 \mathrm{~cm} \times 1.0 \mathrm{~cm}$ and was weld from one side to a copper wire used for electric connection. The sample was embedded in glass tube using epoxy resin [14]. The electrode was prepared before immersion in the test solution as in case of weight loss method. There are three types of electrodes saturated calomel electrode (SCE) and a platinum coil as reference and auxiliary electrodes, respectively used in galvanostatic polarization method.

A constant quantity of the test solution $(100 \mathrm{~mL})$ was taken in the polarization cell. A time interval of about 30 minutes was given for the system to attain a steady state. Both cathodic and anodic polarization curves were recorded galvanostatically using Amel galvanostat (Model-549) and digital Multimeters (Fluke-73) were used for accurate measurements of potential and current density. All the experiments were carried out at $30 \pm 1{ }^{\circ} \mathrm{C}$ by using an ultra circulating thermostat.

\section{Results and discussion}

\subsection{Weight-loss measurements}

Weight-loss of C-steel was determined at various time intervals in absence and presence of different concentrations of thiazole derivatives, compounds $\left[\mathrm{A}_{1-5}\right]$. The obtained weight loss-time curves are represented in Figure 1 for inhibitor $\left[\mathrm{A}_{1}\right]$, the most effective one. Similar curves were obtained for other inhibitors (not shown).

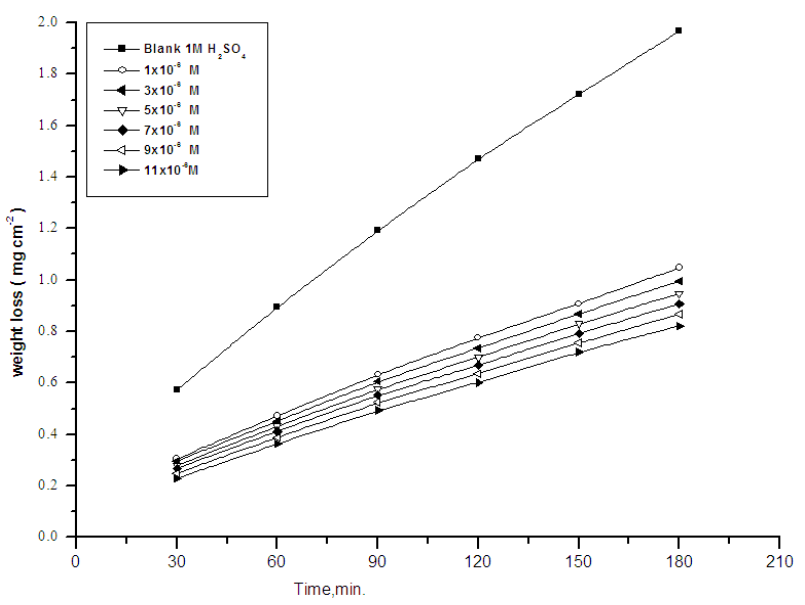

Figure 1. Weight loss-time curves for C-Steel dissolution in $1 \mathrm{M} \mathrm{H}_{2} \mathrm{SO}_{4}$ in absence and presence of different concentration of $\mathrm{A}_{1}$ at $30^{\circ} \mathrm{C}$.

The inhibition efficiency of corrosion was found to be dependent on the inhibitor concentration, nature of substituents and their positions in phenyl ring, with respect to the phenylazo molecule derivatives. The curves obtained in the presence of inhibitors fall significantly below that of free acid. In all cases, the increase in the inhibitor concentration was accompanied by a decrease in weight-loss and an increase in the percentage inhibition. These results lead to the conclusion that, these compounds under investigation are fairly efficient as inhibitors for C-steel dissolution in sulphuric acid solution. Also, the degree of surface coverage $(\theta)$ by the inhibitor, calculated from Eq. [1], would increase by increasing the inhibitor concentration.

$\theta=1-\left(\Delta \mathrm{W}_{\text {inh. }} / \Delta \mathrm{W}_{\text {free }}\right)$

Where $\Delta W_{\text {inh. }}$ and $\Delta W_{\text {free }}$ are the weight losses per unit area in presence and absence of the inhibitor, respectively.

In order to get a comparative view, the variation of the percentage inhibition [I\%] of the five inhibitors with their molar concentrations were calculated according to Eq. [2]; values obtained are summarized in Table 2 .

$\% \mathrm{I}=\theta \times 100$

Table 2. Values of \% inhibition efficiencies of inhibitors for the corrosion of $\mathrm{C}$-steel in $1 \mathrm{M} \mathrm{H}_{2} \mathrm{SO}_{4}$ from weight loss measurements at different concentrations at $30{ }^{\circ} \mathrm{C}$

\begin{tabular}{lccccc}
\hline \multirow{2}{*}{ Conc. (M) } & \multicolumn{5}{c}{ \% Inhibition efficiency } \\
\cline { 2 - 6 } & $\mathbf{A}_{\mathbf{1}}$ & $\mathbf{A}_{\mathbf{2}}$ & $\mathbf{A}_{\mathbf{3}}$ & $\mathbf{A}_{\mathbf{4}}$ & $\mathbf{A}_{\mathbf{5}}$ \\
\hline $\mathbf{1 \times 1 0 ^ { - 6 }}$ & 47.3 & 45.1 & 33.0 & 25.3 & 16.4 \\
$3 \times 10^{-6}$ & 49.6 & 47.1 & 34.3 & 26.5 & 18.6 \\
$5 \times 10^{-6}$ & 51.9 & 49.5 & 36.5 & 27.6 & 20.5 \\
$7 \times 10^{-6}$ & 54.1 & 51.4 & 37.6 & 29.8 & 20.9 \\
$9 \times 10^{-6}$ & 56.8 & 54.0 & 38.7 & 30.9 & 22.0 \\
$11 \times 10^{-6}$ & 59.4 & 56.5 & 50.45 & 32.0 & 25.5 \\
\hline
\end{tabular}

Careful inspection of these results showed that, at the same inhibitor concentration, the order of inhibition efficiencies is as follow: $A_{1}>A_{2}>A_{3}>A_{4}>A_{5}$

The variation of surface coverage determined by weightloss, $\theta$, with the logarithm of the inhibitor concentration, $\log C$, are represented in Figure 2. Temkin isotherm was obeyed for adsorption of thiazole derivatives on the surface of $\mathrm{C}$-steel in 1 $\mathrm{M} \mathrm{H}_{2} \mathrm{SO}_{4}$ acid at $30{ }^{\circ} \mathrm{C}$. The data gave straight lines indicating that Temkin isotherm [15] is valid for these systems. 


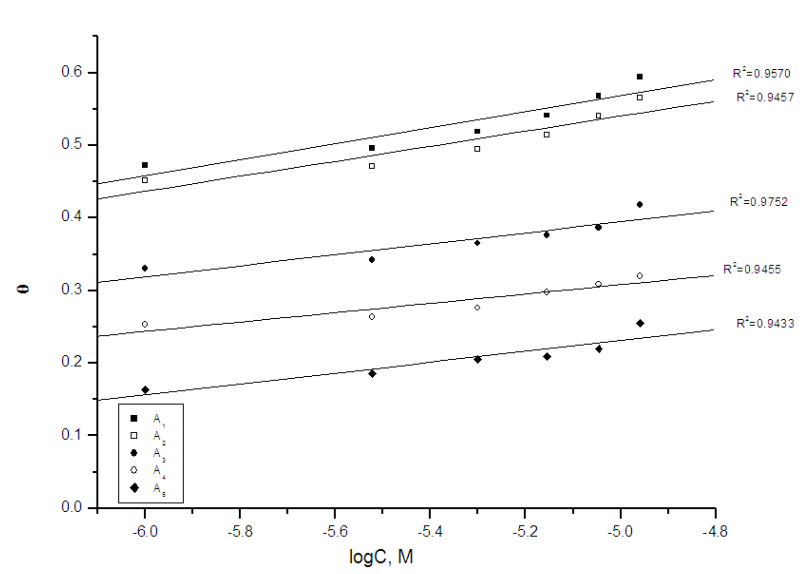

Figure 2. $\theta$ vs $\log \mathrm{C}$ curves for corrosion of C-Steel in $1 \mathrm{M} \mathrm{H}_{2} \mathrm{SO}_{4}$ in presence of different concentration of thiazole derivatives from weight loss measurement at $30^{\circ} \mathrm{C}$.

The Temkin equation is:

$\ln \mathrm{K} \cdot \mathrm{C}=\mathrm{a} \cdot \theta$

On the other hand, it is found that the kinetic-thermodynamic model of El Awady et al [16]:

$\log \theta /(1-\theta)=\log K^{\prime}+\mathrm{y} \log C$

is valid to operate the present adsorption data.

The equilibrium constant of adsorption $K=K^{\prime}(1 / \mathrm{y})$, where $1 / \mathrm{y}$ is the number of the surface active sites occupied by one thiazole molecule and $\mathrm{C}$ is the bulk concentration of the inhibitor. Plotting $\log \theta /(1-\theta)$ against $\log C$ at $30^{\circ} \mathrm{C}$ is given in Figure 3 where straight line relationships were obtained suggesting the validity of this model for all cases studied. The calculated values of $1 / y, K$ and $\Delta G_{\text {ads }}^{\circ}$ are given in Table 3 . Inspection of the data of this Table shows that the large values of $\Delta G_{\text {ads }}^{\circ}$ and its negative sign indicate that the adsorption of thiazole derivatives on C-steel surface is proceeding spontaneously and is accompanied by a highly-efficient adsorption. It is worth noting that the value of $1 / y$ is more than unity. This means that the given inhibitor molecules will occupy more than one active site. In general, the values of $\Delta G^{\circ}$ ads obtained from El Awady et al. [16] model are comparable with those obtained from Temkin isotherms.

Table 3. Inhibitor binding constant $(K)$, Free energy of binding $\Delta G_{\text {ads, }}$ numbe of active sites $(1 / y)$ and later interaction parameter $(a)$ for thiazole derivatives at $303 \mathrm{~K}$.

\begin{tabular}{lcccccc}
\hline \multirow{2}{*}{ Inhibitors } & \multicolumn{3}{c}{ Kinetic Model } & \multicolumn{3}{c}{ Temkin isotherm } \\
\cline { 2 - 7 } & $\mathbf{1} / \boldsymbol{y}$ & $\begin{array}{c}\boldsymbol{K} \\
\left(\mathbf{M}^{-1}\right)\end{array}$ & $\begin{array}{c}-\boldsymbol{\Delta} \boldsymbol{G}_{\text {ads. }} \\
(\mathbf{k J} / \mathbf{m o l})\end{array}$ & $\boldsymbol{a}$ & $\begin{array}{c}\boldsymbol{K} \\
\left(\mathbf{M}^{-1}\right)\end{array}$ & $\begin{array}{c}-\boldsymbol{\Delta} \boldsymbol{G}_{\text {ads. }} \\
(\mathbf{k J} / \mathbf{m o l})\end{array}$ \\
\hline $\mathrm{A}_{1}$ & 9.1 & $163.3 \times 10^{7}$ & 69.63 & 21.1 & $163 \times 10^{8}$ & 69.60 \\
$\mathrm{~A}_{2}$ & 9.6 & $176.4 \times 10^{8}$ & 69.50 & 22.1 & $176 \times 10^{8}$ & 69.42 \\
$\mathrm{~A}_{3}$ & 10.2 & $253.4 \times 10^{6}$ & 64.60 & 23.5 & $253 \times 10^{7}$ & 64.50 \\
$\mathrm{~A}_{4}$ & 16.0 & $228.3 \times 10^{7}$ & 63.12 & 36.8 & $228 \times 10^{8}$ & 63.20 \\
$\mathrm{~A}_{5}$ & 15.7 & $120.6 \times 10^{6}$ & 62.80 & 36.0 & $121 \times 10^{7}$ & 62.74 \\
\hline
\end{tabular}

From these results it may be generalized that the more efficient inhibitor has more negative $\Delta G^{\circ}$ ads. So the order of inhibition efficiencies is as follow: $A_{1}>A_{2}>A_{3}>A_{4}>A_{5}$. This trend will be interpreted latter.

\subsubsection{Effect of temperature}

The effect of temperature on both corrosion and corrosion inhibition of C-steel in $1 \mathrm{M} \mathrm{H}_{2} \mathrm{SO}_{4}$ solution in absence and presence of different concentrations of inhibitors $\left[\mathrm{A}_{1-5}\right]$ at different temperatures ranging from 30 to $50{ }^{\circ} \mathrm{C}$ was investigated.

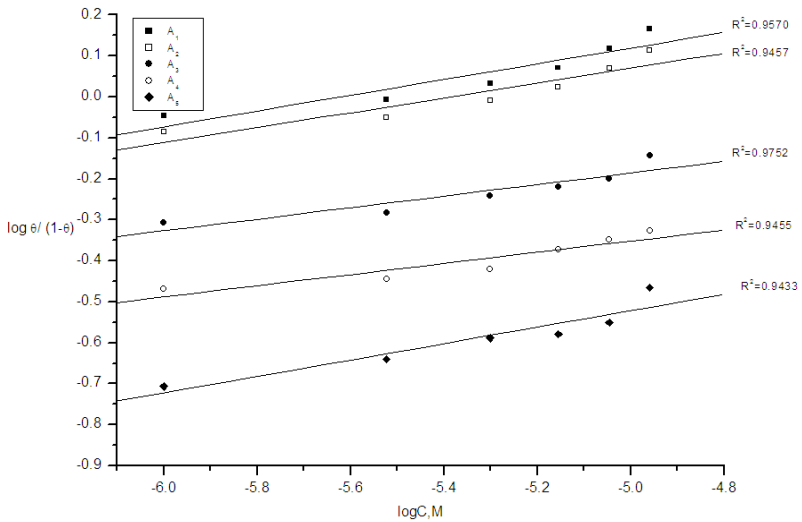

Figure 3. Curve fitting of corrosion data for C-steel in $1 \mathrm{M} \mathrm{H}_{2} \mathrm{SO}_{4}$ in presence of different concentration of thiazole compounds to kinetic model at $30{ }^{\circ} \mathrm{C}$.

Arrhenius plot Eq. [5] of logarithm of the corrosion rate, log $k$, with the reciprocal of absolute temperature, $1 / T$, in absence and presence of $9 \times 10^{-6} \mathrm{M}$ of inhibitors [A1-5] was shown graphically in Figure 4.

$\ln k=\mathrm{B}-\left(E_{\mathrm{a}}{ }^{*} / \mathrm{R} T\right)$

where $B$ is a constant depends on the metal type and electrolyte, and $R$ is the universal gas constant.

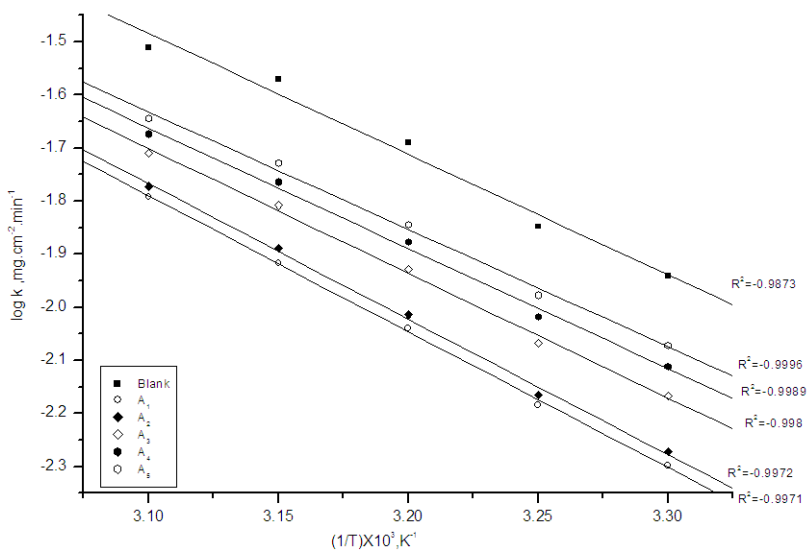

Figure 4. $\log$ corrosion rate (k) vc $1 / \mathrm{T}$ for C-Steel in presence of $9 \times 10^{-6} \mathrm{M}$ thiazole compounds.

From the slopes of the plots, the respective activation energies $\left[E_{\mathrm{a}}^{*}\right]$ were calculated and tabulated in Table 4 . The results show that, the values of activation energy increases in the same order of increasing inhibition efficiency of the inhibitors. It is also indicated that the whole process is controlled by surface reaction, since the energy of activation corrosion process is over $20 \mathrm{~kJ} / \mathrm{mol}$ [17].

Table 4. Activation parameters of the dissolution of C-steel in $1 \mathrm{M} \mathrm{H}_{2} \mathrm{SO}_{4}$ in the absence and presence of $9 \times 10^{-6} \mathrm{M}$ different thiazole compounds.

\begin{tabular}{|c|c|c|c|}
\hline \multirow{2}{*}{$\begin{array}{l}\text { Inhibitor } \\
\text { type }\end{array}$} & \multicolumn{3}{|c|}{ Activation parameters } \\
\hline & $E_{\mathrm{a}}{ }^{*}, \mathrm{~kJ} / \mathrm{mol}$ & $\Delta H^{*}, \mathbf{k J} / \mathbf{m o l}$ & $-\Delta S^{*}, \mathrm{~J} / \mathrm{mol} . \mathrm{K}$ \\
\hline Blank & 41.5 & 41.02 & 154.7 \\
\hline $\mathrm{A}_{1}$ & 49.0 & 46.2 & 136.5 \\
\hline $\mathrm{A}_{2}$ & 48.8 & 45.8 & 137.2 \\
\hline $\mathrm{A}_{3}$ & 44.9 & 43.4 & 146.9 \\
\hline $\mathrm{A}_{4}$ & 43.3 & 42.6 & 151.4 \\
\hline $\mathrm{A}_{5}$ & 42.3 & 41.6 & 153.9 \\
\hline
\end{tabular}

From the results of the effect of temperature, it was observed that the inhibition efficiency increases with increasing the inhibitors concentrations at one hand, and decreases with the rise of temperature on the other hand. This 
means that these compounds are adsorbed physically on C-steel surface.

Enthalpy and entropy of activation $\left(\Delta H^{*}, \Delta S^{*}\right)$ were calculated from transition state theory [18] Table 4:

$$
k=(R T / N h) \exp \left(\Delta S^{*} / R\right) \exp -(\Delta H / R T)
$$

where $h$ is plank's constant, $N$ is Avogadro's number. A plot of $\log (k / T)$ vs. $(1 / T)$, Eq. [6], gave a straight line as shown in Figure 5 for C-steel dissolution in $1 \mathrm{M} \mathrm{H}_{2} \mathrm{SO}_{4}$ in absence and presence of $9 \times 10^{-6} \mathrm{M}$ of inhibitor $\left(\mathrm{A}_{1}\right)$. The order of the inhibition efficiency of the investigated compounds as gathered from the increase in $E_{\mathrm{a}}{ }^{*}$ and $\Delta H^{*}$ and the decrease in $\Delta S^{*}$ values is the same as above. $E_{\mathrm{a}}{ }^{*}$ and $\Delta H^{*}$ of the inhibition process of Csteel in $1 \mathrm{M} \mathrm{H}_{2} \mathrm{SO}_{4}$ in the presence of inhibitors are nearly the same (or slightly higher) that those in free $1 \mathrm{M} \mathrm{H}_{2} \mathrm{SO}_{4}$ solution, indicating that no energy barrier is attained. These data reveal that the inhibition of the corrosion reactions is affected without changing the mechanism. The entropy of activation in the presence and absence of the inhibitor is large and negative. This implies that the activated complex in the rate-determining step represents association rather than dissociation, indicating that a decrease in disorder takes place in going from reactant to the activated complex.

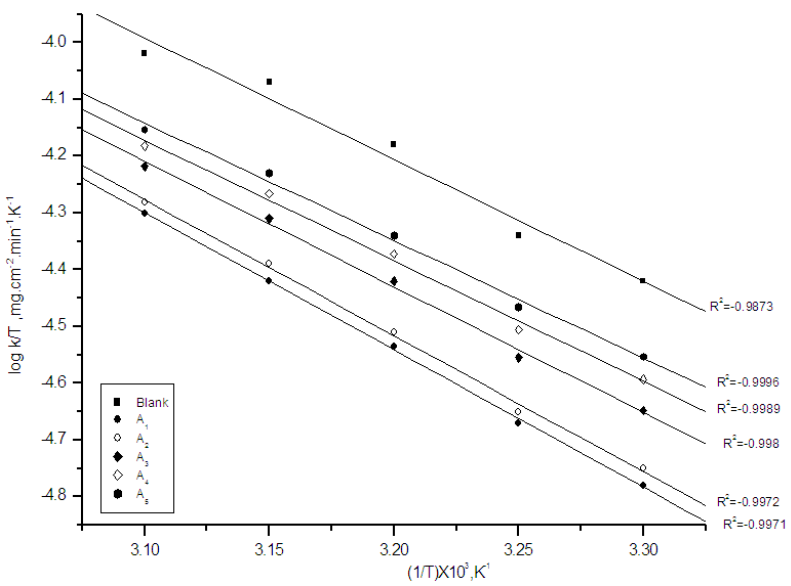

Figure 5. Log corrosion rate/T(kT) vs. 1 /T for C-steel in presence of $9 \times 10^{-6}$ $\mathrm{M}$ thiazole compounds.

\subsubsection{Synergistic effect}

The corrosion behavior of C-steel in $1 \mathrm{M} \mathrm{H}_{2} \mathrm{SO}_{4}$ solution in presence of $1 \times 10^{-3} \mathrm{M}$ potassium bromide, potassium thiocynate and potassium iodide at different concentrations of inhibitors [A1-5] was studied. The obtained weight-loss time curves are represented in Figure 6-8; values obtained are summarized in Table 5. From these values, it is observed that \%I of the inhibitors increases with increasing concentration of inhibitors due to synergistic effects [19]. The synergistic effect of these anions (Br-, SCN- and I-) has been observed [20].This effect depends on the type of anion. From the result it was found that the order of increasing inhibition efficiency in presence of these anions is $\mathrm{KI}>\mathrm{KSCN}>\mathrm{KBr}$ [21]. The strong chemisorptions of $(\mathrm{Br}$, $\mathrm{SCN}^{-}$and $\mathrm{I}^{-}$) anions on the metal surface is responsible for the synergistic effect of bromide, thiothynate and iodide anions in combination with cation of the inhibitor. The cation is then adsorbed by coulombic attraction on the metal surface where bromide, thiocynate and iodide anions are already adsorbed by chemisorption. Stabilization of adsorbed iodide, bromide and thiothynate anions with cations leads to greater surface coverage and therefore greater inhibition. One can conclude that the addition of iodide, bromide and thiothynate ions enhances the inhibition efficiency to a considerable extent, due to the increase of surface coverage in the presence of iodide, bromide and thiothynate ions. The order of investigated compounds remains unchanged, as before. From the previous results, it is known that KI could be considered as one of the effective anions for synergistic action within the investigated inhibitors.

Table 5. Inhibition efficiency of different inhibitors for the corrosion of C-steel in $1 \mathrm{M} \mathrm{H}_{2} \mathrm{SO}_{4}$ containing $1 \times 10^{-3} \mathrm{M} \mathrm{KBr} / \mathrm{KSCN} / \mathrm{KI}$ from weight loss measurements at $30^{\circ} \mathrm{C}$.

\begin{tabular}{lcccccc}
\hline \multirow{2}{*}{ Anions } & Conc. & \multicolumn{5}{c}{ Inhibition efficiency } \\
\cline { 3 - 7 } (M) & KBr & $\mathbf{A}_{\mathbf{1}}$ & $\mathbf{A}_{\mathbf{2}}$ & $\mathbf{A}_{\mathbf{3}}$ & $\mathbf{A}_{\mathbf{4}}$ & $\mathbf{A}_{\mathbf{5}}$ \\
& 0.0 & 22.2 & 22.2 & 22.2 & 22.2 & 22.2 \\
& $1 \times 10^{-6}$ & 62.3 & 59.9 & 55.4 & 52.2 & 50.3 \\
& $3 \times 10^{-6}$ & 66.2 & 63.7 & 58.5 & 56.0 & 52.9 \\
& $5 \times 10^{-6}$ & 70.7 & 66.6 & 61.1 & 58.5 & 55.4 \\
& $7 \times 10^{-6}$ & 75.2 & 70.0 & 66.2 & 61.1 & 57.3 \\
& $9 \times 10^{-6}$ & 79.6 & 73.3 & 69.4 & 66.2 & 60.4 \\
& $11 \times 10^{-6}$ & 84.7 & 76.4 & 72.6 & 69.4 & 62.3 \\
$\mathrm{KSCN}$ & 0.0 & 28.8 & 28.8 & 28.8 & 28.8 & 28.8 \\
& $1 \times 10^{-6}$ & 67.6 & 63.8 & 57.4 & 55.4 & 53.5 \\
& $3 \times 10^{-6}$ & 72.7 & 66.6 & 60.6 & 59.3 & 56.8 \\
& $5 \times 10^{-6}$ & 76.5 & 69.5 & 65.0 & 61.9 & 59.3 \\
& $7 \times 10^{-6}$ & 80.9 & 73.3 & 69.5 & 65.7 & 62.4 \\
& $9 \times 10^{-6}$ & 84.1 & 77.2 & 73.3 & 70.1 & 65.0 \\
& $11 \times 10^{-6}$ & 87.3 & 82.2 & 76.5 & 74.6 & 66.9 \\
$\mathrm{KI}$ & 0.0 & 40.4 & 40.4 & 40.4 & 40.4 & 40.4 \\
& $1 \times 10^{-6}$ & 73.4 & 68.2 & 60.0 & 61.3 & 57.4 \\
& $3 \times 10^{-6}$ & 78.4 & 71.5 & 65.1 & 66.6 & 61.9 \\
& $5 \times 10^{-6}$ & 81.6 & 74.0 & 67.7 & 69.6 & 63.2 \\
& $7 \times 10^{-6}$ & 84.2 & 77.7 & 71.5 & 73.4 & 65.7 \\
& $9 \times 10^{-6}$ & 88.0 & 82.8 & 75.3 & 76.5 & 68.9 \\
& $11 \times 10^{-6}$ & 91.1 & 86.6 & 80.3 & 79.1 & 71.5 \\
\hline
\end{tabular}

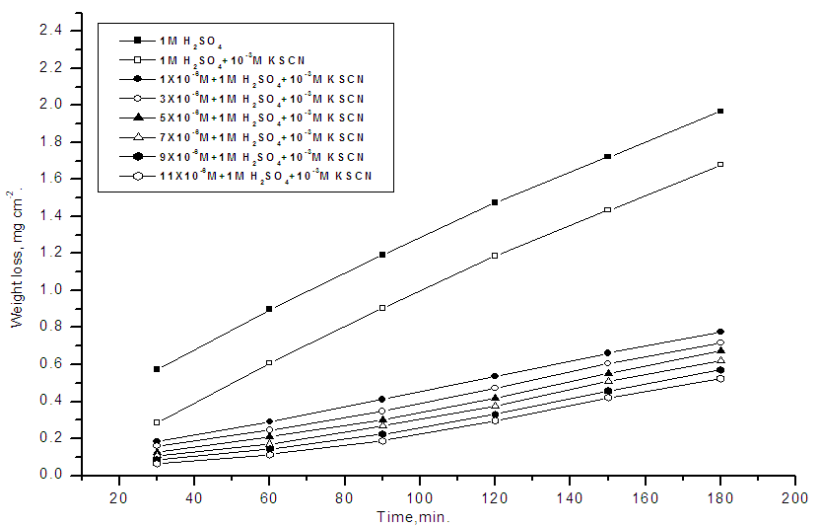

Figure 6. Weight loss-time curves for C-Steel dissolution in $1 \mathrm{M} \mathrm{H}_{2} \mathrm{SO}_{4}$ with and without addition of $1 \times 10^{-3} \mathrm{M} \mathrm{KBr}$ in presence of different concentrations of $\mathrm{A}_{1}$ at $30^{\circ} \mathrm{C}$

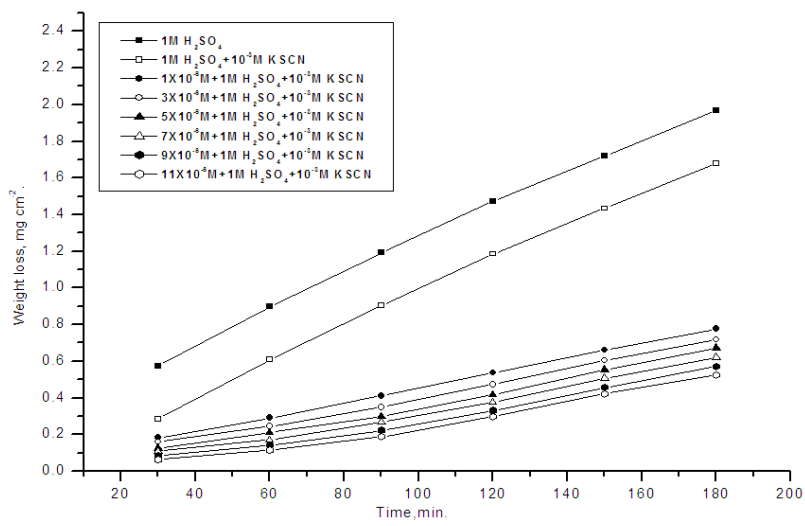

Figure 7. Weight loss-time curves for C-Steel dissolution in $1 \mathrm{M} \mathrm{H}_{2} \mathrm{SO}_{4}$ with and without addition of $1 \times 10^{-3} \mathrm{M}$ KSCN in presence of different concentrations of $\mathrm{A}_{1}$ at $30{ }^{\circ} \mathrm{C}$ 
Table 6. Electrochemical parameters for $\mathrm{C}$-steel in $1 \mathrm{M} \mathrm{H}_{2} \mathrm{SO}_{4}$ with and without different concentrations of inhibitors at $30{ }^{\circ} \mathrm{C}$.

\begin{tabular}{|c|c|c|c|c|c|c|c|}
\hline Inhibitors & Conc. (M) & $i_{\text {corr }}\left(\mathrm{mA} \cdot \mathrm{cm}^{-2}\right)$ & $-E_{\text {corr }}(\mathrm{mv})$ & $\beta_{\mathrm{a}}\left(\mathrm{mvdec}^{-1}\right)$ & $-\beta_{c}\left(m v\right.$ dec$\left.^{-1}\right)$ & $\theta$ & $\% I$ \\
\hline \multirow[t]{7}{*}{$\mathrm{A}_{1}$} & 0.00 & 187.5 & 475 & 56 & 86 & - & - \\
\hline & $1 \times 10^{-6}$ & 130.0 & 491 & 55 & 51 & 0.3066 & 30.7 \\
\hline & $3 \times 10^{-6}$ & 121.6 & 479 & 38 & 52 & 0.3515 & 35.2 \\
\hline & $5 \times 10^{-6}$ & 113.5 & 482 & 50 & 53 & 0.3946 & 39.5 \\
\hline & $7 \times 10^{-6}$ & 87.1 & 475 & 42 & 55 & 0.5355 & 53.6 \\
\hline & $9 \times 10^{-6}$ & 69.5 & 473 & 35 & 48 & 0.6293 & 63.0 \\
\hline & $11 \times 10^{-6}$ & 63.6 & 472 & 32 & 48 & 0.6608 & 66.1 \\
\hline \multirow[t]{6}{*}{$\mathrm{A}_{2}$} & $1 \times 10^{-6}$ & 145.2 & 473 & 56 & 86 & 0.2256 & 22.6 \\
\hline & $3 \times 10^{-6}$ & 133.1 & 476 & 53 & 75 & 0.2901 & 29.0 \\
\hline & $5 \times 10^{-6}$ & 121.6 & 480 & 55 & 65 & 0.3515 & 35.2 \\
\hline & $7 \times 10^{-6}$ & 106.4 & 481 & 45 & 54 & 0.4325 & 43.3 \\
\hline & $9 \times 10^{-6}$ & 72.6 & 471 & 42 & 54 & 0.6128 & 61.3 \\
\hline & $11 \times 10^{-6}$ & 69.5 & 469 & 45 & 55 & 0.6293 & 63.0 \\
\hline \multirow[t]{6}{*}{$\mathrm{A}_{3}$} & $1 \times 10^{-6}$ & 148.6 & 483 & 60 & 86 & 0.2075 & 20.8 \\
\hline & $3 \times 10^{-6}$ & 141.9 & 485 & 65 & 81 & 0.2432 & 24.3 \\
\hline & $5 \times 10^{-6}$ & 132.5 & 481 & 65 & 80 & 0.2933 & 29.3 \\
\hline & $7 \times 10^{-6}$ & 111.2 & 477 & 55 & 80 & 0.4069 & 40.7 \\
\hline & $9 \times 10^{-6}$ & 75.7 & 473 & 55 & 75 & 0.5962 & 59.6 \\
\hline & $11 \times 10^{-6}$ & 75.0 & 473 & 52 & 62 & 0.6000 & 60.0 \\
\hline \multirow[t]{6}{*}{$\mathrm{A}_{4}$} & $1 \times 10^{-6}$ & 185.8 & 481 & 62 & 82 & 0.0090 & 1.0 \\
\hline & $3 \times 10^{-6}$ & 162.6 & 476 & 62 & 86 & 0.1328 & 13.3 \\
\hline & $5 \times 10^{-6}$ & 154.9 & 475 & 60 & 84 & 0.1738 & 17.4 \\
\hline & $7 \times 10^{-6}$ & 133.1 & 476 & 58 & 82 & 0.2901 & 29.0 \\
\hline & $9 \times 10^{-6}$ & 115.9 & 473 & 56 & 82 & 0.3818 & 38.2 \\
\hline & $11 \times 10^{-6}$ & 113.8 & 476 & 55 & 85 & 0.3930 & 39.3 \\
\hline \multirow[t]{6}{*}{$\mathrm{A}_{5}$} & $1 \times 10^{-6}$ & 186.5 & 475 & 65 & 88 & 0.0053 & 0.50 \\
\hline & $3 \times 10^{-6}$ & 180.8 & 480 & 70 & 92 & 0.0357 & 3.60 \\
\hline & $5 \times 10^{-6}$ & 155.6 & 478 & 64 & 92 & 0.1701 & 17.0 \\
\hline & $7 \times 10^{-6}$ & 138.7 & 479 & 68 & 92 & 0.2603 & 26.0 \\
\hline & $9 \times 10^{-6}$ & 121.6 & 475 & 65 & 91 & 0.3515 & 35.2 \\
\hline & $11 \times 10^{-6}$ & 115.2 & 472 & 62 & 90 & 0.3856 & 38.6 \\
\hline
\end{tabular}

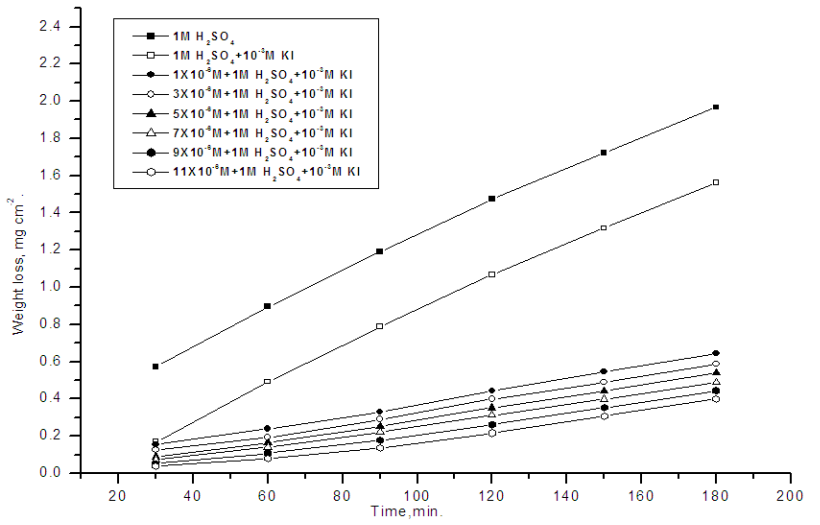

Figure 8. Weight loss-time curves for C-Steel dissolution in $1 \mathrm{M} \mathrm{H}_{2} \mathrm{SO}_{4}$ with and without addition of $1 \times 10^{-3} \mathrm{M} \mathrm{KI}$ in presence of different concentrations of $\mathrm{A}_{1}$ at $30^{\circ} \mathrm{C}$.

\subsection{Galvanostatic polarization measurements}

Figure 9 shows the galvanostatic polarization curves for $\mathrm{C}$ steel dissolution in $1 \mathrm{M} \mathrm{H}_{2} \mathrm{SO}_{4}$ in absence and presence of different concentration of inhibitor $\left[\mathrm{A}_{1}\right]$ at $30{ }^{\circ} \mathrm{C}$. Similar curves were obtained for other inhibitors (not shown).

The numerical values of the variation of the corrosion current density ( $\left.i_{\text {corr. }}\right)$, the corrosion potential $\left(E_{\text {corr. }}\right)$, Tafel slopes $\left(\beta_{a} \& \beta_{c}\right)$, degree of surface coverage $(\theta)$ and the inhibition efficiency (\%I) with the concentrations of inhibitors $\left(\mathrm{A}_{1-5}\right)$ are given in Table 6 . The results indicate that:

1- The cathodic and anodic curves obtained exhibit Tafeltype behavior. Addition of thiazole derivatives increased both the cathodic and anodic overvoltages and the presence of pyrazolone derivatives in solution inhibits both the hydrogen evolution and the anodic dissolution processes.

2- The corrosion current density ( $\left.i_{\text {corr. }}\right)$ decreases with increasing the concentrations of the thiazole derivatives which indicates that these compounds acts as inhibitors, and the degree of inhibition depends on the concentration and type of inhibitors present.

3- The slopes of the anodic and the cathodic Tafel lines $\left(\beta_{a}\right.$ $\& \beta_{c}$ ) were slightly changed on increasing the concentration of the tested compounds. This indicates that there is no change of the mechanism of inhibition in presence and absence of inhibitors. The thiazole derivatives are mixed-type inhibitors, but the cathode is more polarized than the anode when an external current was applied. The higher values of Tafel slopes can be attributed to surface kinetic process rather the diffusion-controlled process.

4- The orders of inhibition efficiency of all inhibitors at different concentrations as given by polarization measurements are listed in Table 7. The results are in good agreement with that obtained from weight-loss measurements.

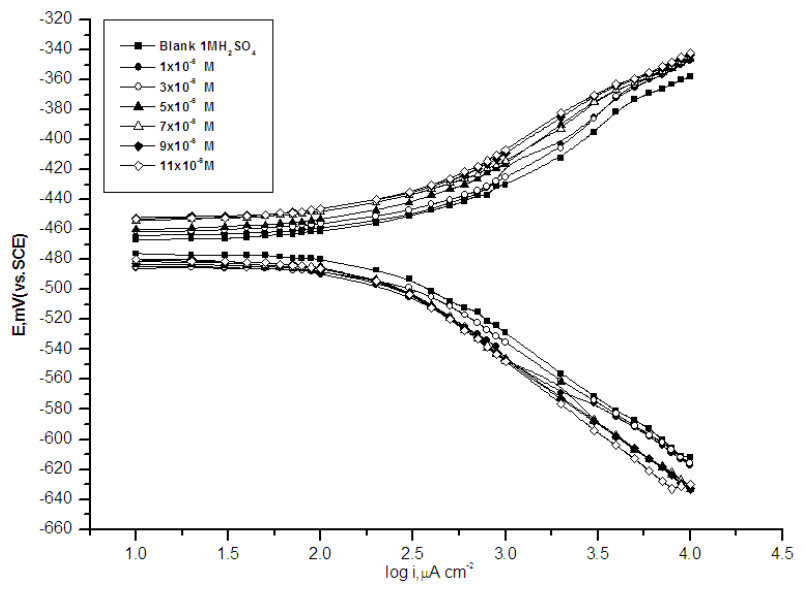

Figure 9. Polarization curves for the dissolution C-Steel in $1 \mathrm{M} \mathrm{H}_{2} \mathrm{SO}_{4}$ in presence and absence of different concentrations of $\mathrm{A}_{1}$ at $30^{\circ} \mathrm{C}$. 


\subsection{Chemical structure and corrosion inhibition}

Variation in structure of inhibitors molecules $\left[\mathrm{A}_{1-5}\right]$ takes place through the phenylazo group. So, the inhibition efficiency will depends on this part of the molecule.

A skeletal representation of the proposed mode of adsorption of studied compounds is shown in Figure 10 and clearly indicates the active adsorption centers.

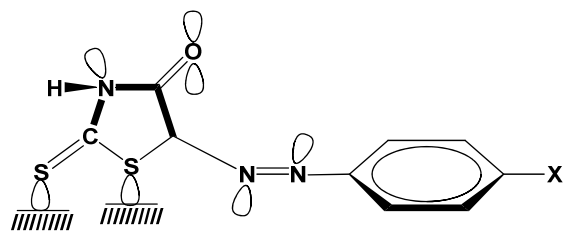

$$
\begin{array}{cc}
\mathrm{X}:-\mathrm{OCH}_{3} & \left(\mathrm{~A}_{1}\right) \\
-\mathrm{CH}_{3} & \left(\mathrm{~A}_{2}\right) \\
-\mathrm{H} & \left(\mathrm{A}_{3}\right) \\
-\mathrm{Cl} & \left(\mathrm{A}_{4}\right) \\
-\mathrm{NO}_{2} & \left(\mathrm{~A}_{5}\right)
\end{array}
$$

Figure 10. Skeletal representation of the mode of adsorption of inhibitor compounds.

This order of increased inhibition efficiency of the additives can be accounted for in terms of polar effect [22] of the psubstituents on the phenylazo group. This behavior can be rationalized on the basis of the structure - corrosion inhibition relationship of organic compounds. Linear Free Energy Relationship (LFER) has previously been used to correlate the inhibition efficiency of organic compounds with their Hammett substituent constant [23], the LFER or Hammett relation is given by [24]:

$\log k$ or $\% \mathrm{I}=-\rho \sigma$

where, $\rho$ is the reaction constant. Those substituents which attract electrons from the reaction center are assigned positive $\sigma$ values and those which are electron donating have negative $\sigma$ values. Thus $\sigma$, is a relative measure of the electron density at the reaction center. The slope of the plot of \%I or log $k$ vs. $\sigma$ is $\rho$ and its sign indicates whether the process is inhibited by an increase or decrease of electron density at the electron center. Figure 11 shows that thiazole derivatives give a good correlation line $(\rho=-29.8)$ which shows a weak dependence of adsorption character of the reaction center on the electron density of the ring with electron releasing substituents increasing inhibition.

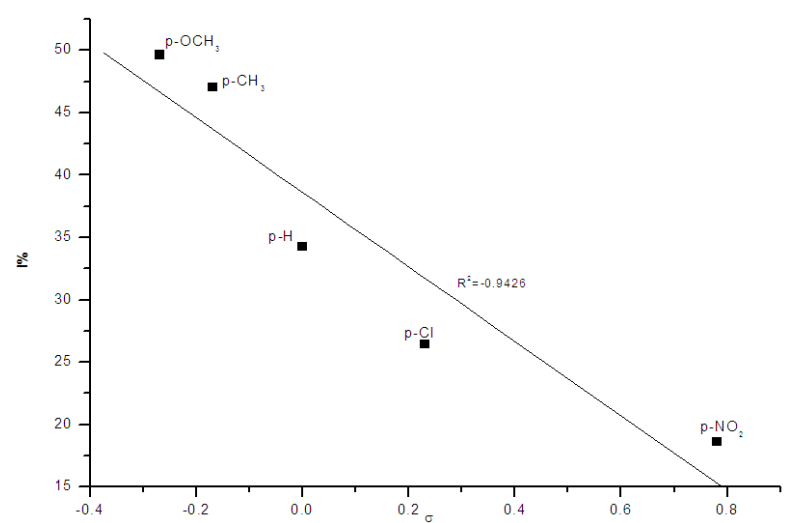

Figure 11. Variation of the inhibition efficiency (I\%) with the substituent constant $(\sigma)$ of the substituent group in para position on phenyl ring of azothiazole derivatives.
The weak dependence of the adsorption character of the reaction center of thiazole derivatives on the electron density of the ring may be due to the centers of adsorption is not thoroughly conjugated to the ring. Compound $A_{1}$ is the most efficient inhibitor because of the presence of highly electron releasing $\mathrm{p}-\mathrm{OCH}_{3}$ group $(\sigma=-0.27)$ which enhances the delocalized $\pi$-electrons on the molecule and also may add an additional active center to the molecule due to its oxygen atom. Compound $\mathrm{A}_{2}$ comes after compound $\mathrm{A}_{1}$ in inhibition efficiency. Because it has $\mathrm{p}-\mathrm{CH}_{3}$ in the phenylazo group with $(\sigma=-0.17)$ lower Hammett constant and hence lower sharing electron density to the molecule. Compounds $\mathrm{A}_{3}, \mathrm{~A}_{4}$ and $\mathrm{A}_{5}$ come after compounds $A_{1}$ and $A_{2}$ because they have positive $\sigma$ values $\left(\sigma_{H}=0\right.$, $\sigma_{\mathrm{Cl}}=+0.23$ and $\sigma_{\mathrm{NO} 2}=+0.78$ ), and hence lower electron sharing to their molecules. The inhibition efficiency of these molecules is parallel to the increased order of electron withdrawing (electrophilic) character of these groups.

On the light of the previous discussions, the nature of substituted groups, whether electron donating or withdrawing reflects its effect on the inhibition efficiency. One can say that the methyl and methoxy groups increase the electron density on the active centers, consequently, the inhibition efficiency increases. It follows that the methoxy groups more efficient than the methyl one. From structural organic point of view, both methyl and methoxy groups have $+R$ effect but the inductive effect is $+\mathrm{I}$ and $-\mathrm{I}$, respectively. The methyl group has $+R$, but its effect is very little as a result of hyper conjugation (Scheme 2).

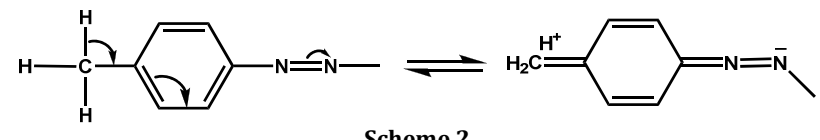

Scheme 2

In the case of methoxy group, the effect of $+\mathrm{R}$ is large and also the inductive effect, -I, thus, Scheme 3:

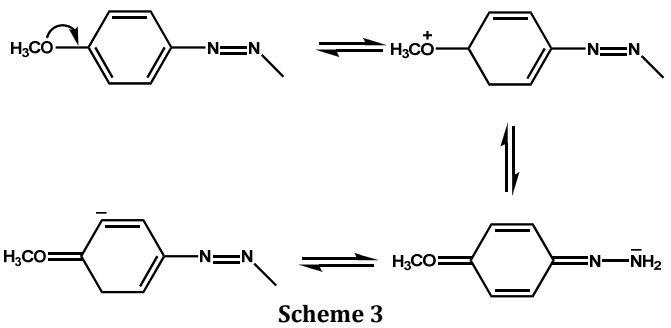

Also methoxy group may add an additional active center and this increases the inhibition efficiency in case of methoxy group than in case of methyl group. On the other hand, the low efficiency of nitro derivatives than methyl and methoxy derivatives may due to:

(i) Its highest electrophilic character,

(ii) it's easily reduction in acid medium and

(iii) the evolved heat of hydrogenation may aids the desorption of the molecules.

In addition inhibitor (IV) is the least efficient inhibitor; this is due to the presence of $-\mathrm{NO}_{2}$ group.

\section{Conclusions}

1. These compounds under investigation, the thiazole derivatives, are fairly efficient inhibitors for $\mathrm{C}$-steel dissolution in $1 \mathrm{M} \mathrm{H}_{2} \mathrm{SO}_{4}$.

2. The adsorption of these compounds on C-steel surface was found to obey Temkin's adsorption isotherm.

3. From the effect of temperature, the activation parameters for the corrosion process $\left(E_{\mathrm{a}}{ }^{*}, \Delta H^{*}, \Delta S^{*}\right.$ and $\Delta G^{*}$ ads $)$ were calculated. 
4. Galvanostatic polarization data indicate that, these compounds are mixed-type inhibitors, but the cathode is more polarized than the anode when an external current was applied.

5. The order of inhibition efficiency of all inhibitors as given by polarization measurements is in good agreement with that obtained from weight-loss measurements. This order was explained on the basis of the chemical structure and adsorption active centers of the compound.

\section{References}

[1]. Huilong, W.; Jiashen, Z.; Jing, L. Anti-Corros. Meth. M. 2002, 49(2), 127132.

[2]. Saeed, T.; Ali, S. A.; Rahman, S. U. Anti-Corros. Meth. M. 2003, 50(3), 201-207.

[3]. Atia, A. A.; Saleh, M. M. J. Appl. Electrochem. 2003, 33(2), 171-177.

[4]. Tamilselvi, S.; Rajeswari, S. Anti-Corros. Meth. M. 2003, 50(3), 223231.

[5]. Keera, S. T. Anti-Corros. Meth. M. 2003, 50(4), 280-285.

[6]. Wang, H. L., Liu, R. B.; Xin, J. Corros. Sci. 2004, 46(10), 2455-2466.

[7]. Fouda, A. S.; Mostafa, H. A.; El-Taib-Heakel, F.; Elewady, G. Y. Corros. Sci. 2005, 47(8), 1988-2004.

[8]. Migahed, M. A.; Mohamed, H. M.; Al-Sabagh, A. M. Mater. Chem. Phys. 2003, 80(1), 169-175.

[9]. Soror, T. Y.; El-Ziady, M. A. Mater. Chem. Phys. 2003, 77 (3), 697-703.

[10]. Lebrini, M.; Lagrenee, H.; Vezin, H.; Gengembre, L.; Bentiss, F. Corros. Sci. 2005, 47(2), 485-505.

[11]. Mubarak, A. T. J. Sol. Chem. 2004, 33(2), 149-155.

[12]. El-Bindary, A. A.; El-Sonbati, A. Z.; El-Mosalamy, E. H.; El-Santawy, E. M. Spectrochim. Acta Part A 2001, 57(12), 2359-2365.

[13]. Fouda, A. S.; El-Kaabi, S. S.; Mohamed, A. K. Corros. Prevent Contr. 1990, 37(6), 164-165.

[14]. Otieno-Alego, V.; Hope, G. A.; Flitt, H. J.; Cash, G. A.; Schweinsberg, D. P. Corros. Sci. 1992, 33(11), 1719-1734

[15]. Hoar, T. P.; Holliday, R. D. J. Appl. Chem. 1953, 3(11), 502-513.

[16]. El-Awady, Y. A.; Ahmed, A. I. J. Ind. Chem. 1985, 24A, 601-606

[17]. Al-Neami, K. K.; Mohamed, A. K.; Kenawy, I. M.; Fouda, A. S. Monatsh Chem. 1995, 126, 369-376.

[18]. Haladky, K.; Collow, L.; Dawson, J. Br. Corros. J. 1980, 15, 20-21.

[19]. Caliskan, N.; Bilgic, S. Appl. Surf. Sci. 2000, 153, 128-133.

[20]. Khamis, E.; El-Ashry, E. S. H.; Ibrahim, A. K. Br. Corrosion J. 2000 35(2), 150-154.

[21]. Fouda, A. S.; Al-Sarawy, A. A.; El-Katori, E. E. Desalination, 2006, 201, $1-13$.

[22]. Hammett, L. P. Physical Organic Chemistry, McGraw-Hill Book Co., N.Y., 1940

[23]. Donahue, F. M.; Nobe, K. J. Electrochem. Soc. 1965, 112(3), 886-891.

[24]. Smialowska, Z. S.; Kaminski, M. Corros. Sci. J. 1973, 13(1), 1-10. 